2016

\title{
Words Matter: Discourse and Numeracy
}

Samuel L. Tunstall

Michigan State University, stunstal@trinity.edu

Follow this and additional works at: https://digitalcommons.usf.edu/numeracy

Part of the Applied Linguistics Commons, and the Science and Mathematics Education Commons

\section{Recommended Citation}

Tunstall, Samuel L.. "Words Matter: Discourse and Numeracy." Numeracy 9, Iss. 2 (2016): Article 5. DOI: http://dx.doi.org/10.5038/1936-4660.9.2.5 


\title{
Words Matter: Discourse and Numeracy
}

\begin{abstract}
Here I discuss elements of critical discourse analysis (CDA) and their importance in relation to quantitative literacy (QL). Through an overview of theory, synthesis of research, and examples, I argue that the discursive nature of textbooks has a nontrivial impact on students' mathematical dispositions - an important component of QL. In particular, texts are a means of disseminating the culture of mathematics, one which has a tendency to paint mathematics as esoteric and male-dominated. Such a characterization has profound implications for the numeracy community, one of which is that we cannot assume that changes in curriculum are sufficient for effecting QL -- simply transitioning to more contextualized mathematics is not enough. Furthermore, it is critical that we examine our own discourse--whether spoken or through text--for ways in which we may be implicitly or explicitly prolong a view of mathematics in which students have little agency.
\end{abstract}

\section{Keywords}

textbooks, discourse, quantitative literacy, numeracy, agency, authority

Creative Commons License

(c) (1) (9)

This work is licensed under a Creative Commons Attribution-Noncommercial 4.0 License

\section{Cover Page Footnote}

Samuel Luke Tunstall is a graduate student in mathematics education and University Distinguished Fellow at Michigan State University. He has taught at multiple levels and is interested in curricula that promote quantitative literacy. In particular, he has an interest in post-secondary mathematics courses and the ways in which they can promote numeracy. 


\section{Introduction}

As educated men and women are expected to know something of history, literature, and art, so should they know-at least in general terms-something of the history, nature, and role of mathematics in human culture. (Steen 2001, 11)

What are the repercussions of the quotation above? Are we to accept the quotation without question? How can we unpack the layers of complexity engendered through the use of the terms "educated," "history," and "culture”? Whose culture are we describing the impact of mathematics on? The purpose of this perspective paper is to orient the readers of Numeracy to the foundations of critical discourse analysis (CDA) and its implications for quantitative literacy (QL, or numeracy) education at the secondary and post-secondary levels. My aim is not to provide definitive answers to the questions above - such would contradict the purpose of the paper. Instead, my goal is to provide a lens to inform one's own answers and galvanize new questions. The topic I discuss is the following: what effect does discourse have in fostering (or inhibiting) numeracy, and what implications do these effects have for our community? To narrow my scope, I limit my synthesis to textbooks, where the text as a whole constitutes discourse (Olson 1980); notwithstanding this restriction, parallels to oral discourse will be apparent. I argue that the discursive nature of a text has a nontrivial effect on students' views of mathematics; these views inform students' dispositions-a significant component of numeracy (Wilkins 2000, 2010). Given that QL-focused courses are terminal for most students, QL educators would be wise in paying careful attention to the books (and words) they choose. Furthermore, my analysis suggests that the numeracy community has room to grow; indeed, while we have made significant advances with respect to pedagogy and curriculum over the past two decades, discourse is an arena we have yet to enter.

Before proceeding, note an assumption in this piece: the vast majority of mathematics instructors at the postsecondary level have no formal background in education or in linguistics (Falk 2012). When instructors choose textbooks for the courses they teach-assuming they have a choice at all-a critical examination of the text's discourse is likely absent from this process. Additionally, I assume that students in the courses read the text in some capacity. Both of these assumptions are reasonable.

With these suppositions in hand, I begin with a brief operationalization of QL and key components within its constitution. This overview will provide a base to reference to as I trace the discursive work of various scholars and those who have applied said work. Throughout the tracing I will include illustrative examples of how elements of discourse might apply to one's own courses. My conclusion will point to future tasks for the community of QL educators. 


\section{Quantitative Literacy}

The notion of numeracy is not a novel one (Steen 1989); however, its presence within a research setting is (Scheaffer 2008). In this paper I use numeracy and QL interchangeably, while recognizing that many have provided commentary regarding the nuances in their respective definitions (Vacher 2014; Karaali et al. 2016). With that said, the following operationalization of QL from the Mathematical Association of America's Special Interest Group in Quantitative Literacy is common:

QL can be described as the ability to adequately use elementary mathematical tools to interpret and manipulate quantitative data and ideas that arise in an individual's private, civic, and work life. Like reading and writing literacy, quantitative literacy is a habit of mind that is best formed by exposure in many contexts. (SIGMAA QL 2004)

This definition suggests that a quantitatively literate individual should be able to work successfully with numbers as they manifest in day-to-day living whether on talk shows, in the doctor's office, or on a nutrition label, among other places. Regarding mathematical content, Hughes-Hallett (2003) suggests that the foundations of QL are laid in elementary and middle school; necessary topics include percentages, ratios, and basic statistics, among others.

What the above definition from SIGMAA QL does not capture is the affective component of numeracy. Wilkins (2000, 2010) argues that one's disposition to use numbers in day-to-day life as well as their view of the social utility of mathematics are important components for QL. He notes that individuals persist in tasks they value; accordingly, someone with a positive disposition towards mathematics is likely to employ a quantitative lens if a situation warrants it. Additionally, Apple (1992) and Orrill (2001) argue that literacy should also be "critical" in the sense that a student should have the ability to use "mathematical knowledge as part of a process of social criticism and renewal” (Apple 1992, 429). A critical disposition, then, is one's tendency to appraise mathematics as well as to use the subject in appraising society. Note this disposition is not equivalent to the type of disposition fostered through attending to the call in the epigraph; indeed, appreciating the contribution of mathematics to culturewithout any note of its oppressive nature-is misleading. Accordingly, I view numeracy as composed of four components: elementary mathematical content knowledge, one's disposition to use mathematics in daily life, one's view of the social utility of the discipline, and a critical view of the discipline. The latter three components are important in this paper, as I argue that discourse has a significant influence on students' dispositions. In particular, when writing QL texts, we might consider how they "position" students, as the discursive choices we make provide a certain level of autonomy in deciding what mathematics they should learn and 
the means by which they learn it. With this multifaceted framework for numeracy in hand, it is important to establish its importance.

Steen's (2001) Mathematics and Democracy marks the seminal twenty-first century plea for numeracy at all levels. Steen-on behalf of a quantitative literacy design team - begins the edited volume with the notion that the world is "awash in numbers," then proceeds to note that it is not mere mathematics that students need to succeed, but rather the tools of quantitative literacy (Steen 2001, 1). He continues in arguing that numeracy enables one to participate in democracy (numbers inundate election cycles), to participate in other disciplines and professions (e.g., sociology, computer science, law, entrepreneurship), as well as to manage one's personal finances and health, among other things. This participation is not simply rhetoric. The connections between numeracy and the aforementioned participation manifest in quantitative studies.

Indeed, researchers have found that mathematical ability is connected to both wage increases and likelihood of fulltime employment (Eide and Grogger 1995; Levy et al. 1995; Rivera-Batiz 1992). In addition, some have linked numeracy with better decision-making (Jasper et al. 2013), nutrition label understanding (Rothman et al. 2006), as well as with better risk comprehension in health care (Fagerlin et al. 2007; Lipkus and Peters 2009). Taken together, it is clear that numeracy is linked with positive life outcomes. Note that numerous others have commented on the importance of numeracy; more in-depth treatment of this topic is beyond the scope of this paper (but see Madison and Steen 2008, Steen 2004.)

\section{The Power of Language}

\section{Critical Discourse Analysis}

The critical view of language I adopt is not novel in work outside of mathematics; rather, it is the use of critical discourse analysis (CDA), of which systemic functional linguistics forms the backbone (Rogers 2004). Halliday (1978) described systemic functional linguistics as the empirical study of how the linguistic structure of discourse relates to the function of language. He theorized three systemic means (or metafunctions) through which discourse operates: the interpersonal, ideational, and textual. While the latter two are important, I focus on the former. The interpersonal metafunction is the means through which a speaker imposes his or her views and attitudes within discourse; in essence, it is how one establishes relationships - if there are to be any-within a text or conversation (I further elaborate this point in a coming section).

The key revelation in Halliday's view is that there is a patterned function behind language. From a systemic standpoint, Kress and Hodge (1979, 13) note that language, whether spoken or written, serves as a "medium of consciousness for a society, its form of consciousness externalized.” Halliday $(1973,8)$ agrees, 
writing that "Language is the primary means for the transmission of culture from one generation to the next." Applying this notion to mathematics and to numeracy, teachers (or textbooks) pass on the "culture" of the discipline. This passage is potentially problematic, given that many view mathematics as enshrouded within the ether of theory (Kennedy 2001). For postsecondary students enrolled in a terminal mathematics course, it is important not only that the discourse suggests that they are fully able to do mathematics, but also that it relates to mathematics worthy of students' time.

Additionally, because historically mathematics and mathematics education (in the U.S.) has systemically excluded people of color, as well as females, and working-class people (Secada 1989, as cited in Apple 1992; Martin et al. 2010), and that such groups often communicate mathematics in manners differently than those within traditional mathematics (e.g., Carraher et al. 1985), language has the ability to perpetuate the marginalization of historically oppressed groups. ${ }^{1}$ It may be that a group that is systemically excluded from mathematics will face greater challenges in developing numeracy. Given these claims, the following question arises: how does language communicate power?

\section{Conveying Power}

An important notion within CDA is that language is a vehicle for transmitting and perpetuating power (Rogers 2004; Oughton 2007). In Language and Power, Fairclough $(1989,3)$ argues that "Nobody who has an interest in modern society, and certainly nobody who has an interest in relationships of power in modern society, can afford to ignore language.” Traditional discourses within mathematics are especially imperious. As McBride $(1989,45)$ describes, "[Mathematics] is a very controlling discursive system, and its status in our technological society causes individuals to accept this discourse as normal." The reason for this acceptance is that within mathematical discourse exists a positivist epistemology, which contends that one can objectively use tools of the discipline to understand fully the world (Burton 2008); given that many have argued this framework is problematic (e.g., Fendler 2006), it is important to interrogate such discourse.

One instrument of evincing power is through modality (Kress and Hodge 1979). In nearly every utterance a speaker makes, a classification known as modality is used; it serves to qualify the extent to which the statement is likely to be true. For instance, suppose that you are teaching a QL-focused course and are going over the syllabus on the first day of class. There is a nontrivial difference between saying "To be successful in this mathematics course, you must show your work in a logical manner" and, "To be successful in this mathematics course, it is helpful to write your ideas down in a coherent fashion.” The latter statement gives

\footnotetext{
${ }^{1}$ For those interested in the intersection of discourse and marginalization, see (Bourdieu 1977), (Lubienski 2000), or (Zevenbergen 1996).
} 
advice yet yields agency to a mathematics student, whereas the former leaves no room for alternative techniques. Through continued use of such discourse in your course and others, this dearth of agency internalizes within a student the notion that mathematics is a fixed discipline wherein a set body of knowledge exists that there is no room for deviation. Indeed, as Fairclough $(2001,54)$ notes, "A single text on its own is quite insignificant: the effects of media power are cumulative, working through the repetition of particular ways of handling causality and agency, particular ways of positioning the reader, and so forth." This notion suggests that for educators interested in effecting QL, they might be mindful of how they may or may not be perpetuating mathematics as an unyielding discipline. For students to be numerate, it is significant that they have a positive disposition toward mathematics and a recognition that the discipline is not impervious to subjectivity.

Another important vehicle for demonstrating power is positioning. Davies and Harré $(1990,48)$ define positioning as the "discursive process whereby selves are located in conversations as observably and subjectively coherent participants in jointly produced story lines.” In every conversation-whether through text or talk-participants are positioning themselves and being positioned by others. This positioning is a manifestation of Halliday's interpersonal metafunction. As an overt example, when an undergraduate student addresses her mathematics instructor as professor, she is positioning herself as somehow "below" the instructor; on the other hand, if-in her graduate work-she addresses her professor by her first name, she is positioning herself as being on the same level as the professor. One might note that the social curtsies of the aforementioned situation are blatant. I concede this fact. Nevertheless, as Davies and Harré (1990, 48) note, it is "A mistake to assume that...positioning is necessarily intentional." Again, over time and through repeated discourse, we position ourselves and others in specific ways we may not be consciously aware of. A simple, subtle instance is that in the previous example, I used female pronouns in describing both the student and professor. As an author, I am positioning myself as aware of the presence of females within academia; moreover, I am positioning the reader to note that females are there. If, as many texts do (McBride 1989), I always used male pronouns in discourse surrounding higher education or mathematics, the implication to the reader would be that females have no place there.

With this introduction of positioning, note it is a key means by which the author(s) of a text are able to project whom they view as their audience, what role such an audience will have in the text, as well as assumptions they have about those in the audience. If a QL textbook begins with "Though you may have struggled with mathematics in the past," or "Though you may not enter a career in a STEM field," it projects specific assumptions onto the student, positioning them in a specific manner for the remainder of the text. Discourse within a college 
mathematics classroom might take place in the same way. Although the quotations may seem harmless, a key component of numeracy is that people have a disposition to use mathematics in their lives and that they view it as useful. When a text continuously positions a student as incapable of mathematical work, a student will leave the course with that position-one which is not conducive to a quantitative habit of mind. Of course, one might argue that such is necessary in order to write a text with the goals of problem-solving. I will discuss pragmatic steps forward at the end of this paper.

\section{Previous Research on Mathematics Texts}

An earlier example I presented was of an arbitrary text's positioning of the student reader as unlikely to enter a career in a STEM field. This type of interpretation is not novel. Dowling (1996) examined two British mathematics texts from a tracked secondary curriculum, labeled ' $G$ ' and ' $Y$,' performing what he described as a sociological analysis. Notably, although his examination contained elements of critical discourse analysis, he did not use that phrase; instead, he described his process as inductive, wherein he examined the text by looking for salient features of any kind - not just those provided for in a framework.

Dowling looked at both text and image to find that the two books positioned readers differently; whereas the $G$ texts recruited readers to do everyday mathematics using a subordinating positioning voice, the $\mathrm{Y}$ text recruited students to a "yet unknown, esoteric" subject of mathematics (Dowling 1996, 393). The G text apprenticed students to “a non-intellectual occupation” by presenting problems as they would be found in the real world (394). As an example, Dowling noted that as students performed calculations concerning a car's skid distance, and the place to put answers was structured as a police report. In Dowling's language, "The $\mathrm{G}$ text, then, positions its reader voice within a particular, comparatively low status, career trajectory and distributes public domain message to this voice: mathematics is presented as being for participation in the public domain” (395). On the one hand, we see that the $G$ text subtly discouraged students from participation in careers that did not require mathematics - precisely the goal of the course. On the other hand, this language perpetuated the notion within the student's mindset that they were not fit for such "esoteric" mathematics. This suggested mindset is problematic because it is not necessarily the case that the student desires a "non-intellectual" future. Indeed, with tracking systems prevalent in the U.S. (Gamoran 2010), it is highly likely that a student could enter the course without having declared a field of interest. Given my earlier framework of numeracy consisting of elementary mathematical ability in conjunction with a positive disposition, one might ask if the type of text Dowling criticizes is sufficient for numeracy. With students only doing real-world mathematics, this 
answer hinges on the type of disposition that such a text fosters. It may be the case that students learn to view the world with a mathematical lens; however, through the repeated discourse they are exposed to in textbooks, will they have a positive view of mathematics? It depends.

As Dowling pointed out, authors interested in discourse should be wary of the means by which they invite the reader to participate in mathematics. In his analysis of the $\mathrm{G}$ text, he noted that the author connects with the reader by making previous knowledge of domestic affairs requisite for participation in the course; all the while, by insinuating that the text's mathematical lens on domestic affairs is requisite for true participation in said activity, the text contradicts itself. Dowling $(1966,407)$ called this contradiction the "myth of participation" and continued:

Domestic activities, then, are not, in themselves, incorporated into the public domain of school mathematics. Rather, the esoteric domain of school mathematics casts a mythologizing gaze onto these activities, imposing its own structure on them and thus constructing settings for its public domain.

Here Dowling disrupted the notion of "real-world" mathematics as presented in school texts. The notion of what makes problems relevant to students is beyond the scope of this argument. What is relevant is the notion that the text imposes the structure of mathematics' "esoteric domain" upon daily activities. The implication of this imposition is that it fosters a view of mathematics as being arcane and ultimately not pragmatic for students. Dowling is not alone in these findings. Zevenbergen (1998, 2000) notes there is tension that manifests when students encounter language-whether in the classroom or in a textbook - that feigns authenticity (and thus power) while lacking any connection to students' lives. This mode of discourse naturally advantages students who are versed in it, giving them a form of capital that others do not have. Even reform texts are not immune to these issues.

Performing CDA using the method of Fairclough, Le Roux (2008) drew a similar conclusion from a typical word problem taken from a reform-oriented calculus text. Her research grew from a concern about the fidelity of mathematics reform efforts in South Africa. Notwithstanding the notion that "reform curricula portray mathematics as a human activity with applications to real life," she felt key theorized values of the reform-relevance of mathematics and student access to the discipline-did not manifest within textbooks bred from reform. In analyzing the problem, she noted that "The interpreting student is positioned as a student of mathematics who has access to the use of the mathematics register and to the assumptions associated with the school mathematical word problem genre" (Le Roux 2008, 323). This quote suggests that the problem's structure and wording is traditional. Thus, because the analyzed problem was considered to be of the real-world type within the text, her findings further Dowling's notion of 
mathematics" "mythologizing gaze" upon the real-world-now in a reform context. This finding is problematic if one assumes that such efforts are-at least in part-designed to foster numeracy. A host of others have analyzed the values portrayed in mathematics textbooks.

Seah and Bishop (2000) employed coding analysis in examining middleschool mathematics texts in Victoria and Singapore, drawing on Bishop's (1988) complementary pairs of values to inform their coding. Although their focus was not on positioning, it did encompass how mathematics texts construct the discipline for a student. In contrast to the analytical frameworks of Dowling and Le Roux, here Seah and Bishop (2000) used a "nonreactive technique” called content analysis; aiming for a less subjective analysis, they began by coding for ways in which a value might manifest in the text, then objectively searched the text for those codes. Their findings included the texts' emphasis on "control over progress," "mystery over openness," and "specialism over accessibility" (Seah and Bishop 2000, 19). The former means that the texts portray mathematics as fixed and stable (i.e., not subject to change by the student); the middle communicates that the discipline is a mystery, while the latter underscores the notion that the knowledge is not readily accessible to everyone. The texts' esoteric portrayal of mathematics bolsters the findings of Dowling (1966) and Le Roux (2008). Moreover, if one assumes that students accept this construction of the discipline, as well as that other mathematics texts that students encounter are similar, then-relating the findings back to numeracy-it is plausible that over time, students will view mathematics as immutable and irrelevant to their lives.

With a similar attentiveness to the notion of authority amidst reform, HerbelEisenmann (2007) examined the "voice" of a unit in a reform-oriented mathematics text series using CDA. In her analysis, she found no first-person pronouns within the unit, arguing that such an "obfuscation of agency" within the text portrays mathematics as a discipline that can act independently of humans. Her findings suggested that, notwithstanding the goals of the curriculum, "how powerful the hegemony of traditional forms of discourse in mathematics curriculum materials can be” (Herbel-Eisenmann 2007, 361). This finding bolsters those of Seah and Bishop and furthers Dowling's (1966) and Le Roux's (2008) findings in relation to authority.

Extending this work, Herbel-Eisenmann et al. (2010) analyzed "stance bundles" (groupings that communicate personal feelings, attitudes, value judgements, or assessments) within mathematics classroom discourse to see how teachers positioned themselves and students (Biber et al. 2004, 966, as cited in Herbel-Eisenmann et al. 2010, 44). Though their work concentrated on oral discourse, it nevertheless speaks to how a textbook might use stance bundles. They noted that some stance bundles permit choice (e.g., Are you going to...; If you want to...) while others discourage latitude (e.g., You need to do... [clear 
authority]; We are going to... [subtle authority]) (Herbel-Eisenmann et al. 2010, 51); their finding was that the majority of the bundles were of the latter form. Altogether, these authors suggest that mathematics texts, regardless of curricular goals, have the tendency to position students with little choice-a position that is at odds with developing numeracy.

Aside from the examples I have given from arbitrary texts, none of the research has directly related discourse to numeracy. Oughton (2007) did this in performing CDA on the British Skills for Life curriculum, an obligatory set of standards for adult numeracy education in Great Britain. While acknowledging that reform has been helpful for mathematics education (in this context the new Skills for Life curriculum), like Le Roux (2008) and Herbel-Eisenmann (2007), Oughton saw value in critical analysis of the subtleties in fidelity of the discourse to the reform goals. Akin to Dowling (1996), Oughton focused on how the text constructed the ideal reader; extending this work, the analysis also included the place of the teacher within the text. She found that the text constructed the ideal reader of the text as the numeracy teacher, and in turn constructed for the teacher the ideal student. The curricula constructed the learner using deficit, childlike language; it positioned the student with little independence, excluding him or her from academic mathematics. This positioning is certainly problematic for a QLfocused text. In arguing for an alternative, she noted the following: "Numeracy learners could be presented, not within a deficit model as passive and without agency, but as highly motivated, self-directed adults who bring a variety of numerate practices to their learning that can be celebrated and developed" (Oughton 2007, 273).

\section{Implications for the Numeracy Community}

With this discussion in place, a necessary question is: what does it all mean for the numeracy community? In continuing to describe steps toward a "better" discourse for numeracy within texts, Oughton $(2007,272)$ states that "Criticism does not take us anywhere unless we can suggest a better alternative.” Indeed, it is a rather straightforward task to identify and describe a problem. It is difficult to give viable options.

At the level of textbook writing, I return to the notion that texts have authority. Olson $(1980,192)$ notes that books "are taken as the authorized version of a society's valid knowledge.” Accordingly, those writing texts or curricula to foster numeracy might be wary of how they position the reader and portray the discipline. When writing, they could consider the following questions: Are you offering the reader agency to decide what mathematics is important, or to decide how one approaches a problem? What epistemological view do you adopt regarding mathematics, and how does it manifest in your writing? At the meta- 
level, does the text recognize the problematic transfer of school mathematics to mathematics as it manifests in daily life? Such ideals for what mathematics discourse can look like are not mere rhetoric. Boaler (1993) found that students' transfer of mathematical content across different contexts was significantly better when the mathematics curriculum recognized the individual construction of meaning, among other things. This research has direct implications for us, given that a goal of most QL courses is to have students recognize how to apply mathematics in different contexts. Hence, one should ask these questions of themselves throughout their writing.

Regardless of the text that one has, note that at the local level, numeracy instructors are responsible for their use of the textbook within a class. This idea is promising, given that most QL instructors do not write their own textbooks. As Herbel-Eisenmann (2007, 364) states, "Authority may be mediated through the teacher's use of a textbook." Moreover, “As mathematics educators recognize how they encode the authority structures that are implicit in their classroom practice, it becomes possible to envision alternatives and consciously choose what values to communicate" (Herbel-Eisenmann and Wagner 2010, 61). So, if a text contains discourse that conflicts with the affective goals of a course, a teacher can explicitly discuss that issue with the class. He or she might suggest to students that mathematics is a lens to use in their lives when appropriate; that historically it has systemically marginalized some groups within society (Apple 1992), and that students not only have agency in what mathematics they learn, but also in what situations they might use it. The result is that—as Burton $(2008,527)$ phrases itmathematics can be "re-perceived as humane, responsive, negotiable and creative."

Focusing on spoken discourse-with or without any relation to texts - it is important for QL instructors to consider not only how they are portraying mathematics in their teaching, but also to highlight directly for students how discourse positions them. Indeed, in the same respect that texts can encode power structures, so too can the means by which an instructor discusses or portrays mathematics for students. From a practical standpoint, a handful of examples to consider include: forcing students to call you professor; tending to use masculine pronouns; projecting onto students assumptions about their backgrounds, whether cultural or mathematical; telling students that they "need" to do something; and using language that portrays mathematics as a discipline that can solve any problem, among other things. Note I do not use such examples to demonize those who do them; with that said, an awareness of their potential effect is paramount. All of these instances are subtle discursive moves that influence students' views of mathematics. And when such occur in a student's final course in the discipline, it has a lasting footprint on their quantitative disposition. 
Moving beyond an awareness of our own discourse and that of texts, it is fitting to empower students to do the same. Hence, an additional idea for the numeracy community to consider is incorporating critical discourse analysis as part of students' interactions with media articles. Given that many QL-focused courses include the examination of media (e.g., Dingman and Madison 2010), it would be a straightforward task to append such questions to assignments. For a given article, questions could include: how does the piece use language to position the reader (if at all)? Is the reader given the latitude to make conclusions on his or her own? Are claims within the piece coupled with modal qualifiers? Are quantitative arguments portrayed with authority, and if so, how? These new questions, along with the others that ask students about quantitative accuracy, I believe, will promote numeracy as I have described it in my framework.

\section{Acknowledgment}

The author is grateful to the reviewers for their advice in making this piece stronger and more relevant to Numeracy readers.

\section{References}

Apple, M. 1992. "Do the Standards Go Far Enough? Power, Policy and Practice in Mathematics Education.” Journal for Research in Mathematics Education 23 (5): 412-431. http://dx.doi.org/10.2307/749562

Biber, D., S. Conrad, and V. Cortes. 2004. "If You Look at...: Lexical Bundles in University Teaching and textbooks.” Applied Linguistics 25 (3): 371-405. http://dx.doi.org/10.1093/applin/25.3.371 (accessed November 10, 2015).

Bishop, A. J. 1988. Mathematical enculturation: A Cultural Perspective on Mathematics Education. Dordrecht, The Netherlands: Kluwer Academic Publishers. http://dx.doi.org/10.1007/978-94-009-2657-8

Boaler, J. 1993. "Encouraging the Transfer of 'School' Mathematics to the 'Real World' Through the Integration of Process and Content, Context and Culture.” Educational Studies in Mathematics 25 (4): 341-373. http://dx.doi.org/10.1007/BF01273906

Bourdieu, P. 1977. “Cultural Reproduction and Social Reproduction.” In Power and Ideology in Education, ed. J. Karabel, and A. H. Halsey, 487-511. New York, NY: Oxford University Press.

Burton, L. 2008. "Moving towards a Feminist Epistemology of Mathematics.” ZDM Mathematics Education 40 (3): 519-528. http://dx.doi.org/10.1007/s11858-0080109-9

Carraher, T. N., D. W. Carraher, and A. Dias Schliemann. 1985. "Mathematics in the Streets and in Schools.” The British Journal of Developmental Psychology 3 (1): 21. http://dx.doi.org/10.1111/j.2044-835X.1985.tb00951.x (accessed November 10, 2015).

Davies, B., and R. Harré. 1990. "Positioning: The Discursive Production of Selves.” Journal for the Theory of Social Behaviour 20 (1): 43-63. 
http://dx.doi.org/10.1111/j.1468-5914.1990.tb00174.x (accessed November 10, 2015).

Dingman, S. W., and B. L. Madison. 2010. "Quantitative Reasoning in ihe Contemporary World, 1: The Course and its Challenges.” Numeracy 3 (2): Article 4. http://dx.doi.org/10.5038/1936-4660.3.2.4 (accessed December 10, 2014).

Dowling, P. 1996. “A Sociological Analysis of School Mathematics Texts.” Educational Studies in Mathematics 31 (4): 389-415. http://dx.doi.org/10.1007/BF00369156 (accessed November 10, 2015).

Eide, E., and J. Grogger. 1995. “Changes in College Skills and the Rise in the College Wage Premium.” Journal of Human Resources 30 (2): 280-310. http://dx.doi.org/10.2307/146120

Fagerlin, A., P. Ubel, D. Smith, and B. Zikmund-Fisher. 2007. "Making Numbers Matter: Present and Future Research in Risk Communication.” American Journal of Health Behavior 3: 47-56. http://dx.doi.org/10.5993/AJHB.31.s1.7

Fairclough, N. 2001. Language and Power. 2nd ed. New York, NY: Longman.

Falk, E. 2012. Becoming a New Instructor: A Guide for College Adjuncts and Graduate Students. New York, NY: Routledge.

Fendler, L. 2006. "Why Generalizability Is Not Generalizable.” Journal of Philosophy Education 40 (4): 437-449.

Gamoran, A. 2010. "Tracking and Inequality: New Directions for Research and Practice.” In The Routledge international handbook of the sociology of education, ed. M. Apple, S. Ball, and L. Gandin, 214-228. New York, NY: Routledge.

Halliday, M. A. K. 1973. Explorations in the Functions of Language. London: Edward Arnold.

- 1978. Language as Social Semiotic: The Social Interpretation of Language and Meaning. Baltimore, MD: University Park Press.

Herbel-Eisenmann, B. 2007. "From Intended Curriculum to Written Curriculum: Examining the "Voice" of a Mathematics Textbook." Journal for Research in Mathematics Education 38 (4): 344-369.

_ D. Wagner, and V. Cortes. 2010. "Lexical Bundle Analysis in Mathematics Classroom Discourse: The Significance of Stance.” Educational Studies in Mathematics 75 (1): 23-42. http://dx.doi.org/10.1007/s10649-010-9253-6

Hughes-Hallett, D. 2003. "The Role off Mathematics Courses in the Development of Quantitative Literacy.” In Quantitative Literacy: Why Numeracy Matters for Schools and Colleges, ed. B. L. Madison, 91-98. Princeton, NJ: National Council on Education and the Disciplines.

Jasper, J. D., C. Bhattacharya, I. P. Levin, L. Jones, and E. Bossard. 2013. "Numeracy as a Predictor of Adaptive Risky Decision Making.” Journal of Behavioral Decision Making 26 (2): 164-173. http://dx.doi.org/10.1002/bdm.1748 (accessed November 10, 2015).

Karaali, G., Hernandez, E. H., and J. A. Taylor. 2016. "What’s in a Name? A Critical Review of Definitions of Quantitative Literacy, Numeracy, and Quantitative Reasoning.” Numeracy 9 (1): Article 2. http://dx.doi.org/10.5038/1936-4660.9.1.2 (accessed January 21, 2016).

Kennedy, D. 2001. “The Emperor’s Vanishing Clothes.” In Steen 2001, 55-59. 
Kress, G. R., and B. Hodge. 1979. Language as Ideology. Boston: Routledge and Kegan Paul.

Le Roux, K. 2008. "A Critical Discourse Analysis of a Real-World Problem in Mathematics: Looking for Signs of Change.” Language and Education 22 (5): 307326. http://dx.doi.org/10.1080/09500780802152663 (accessed November 10, 2015).

Levy, F., R. J. Murnane, and J. B. Willett. 1995. “The Growing Importance of Cognitive Skills in Wage Determination.” Review of Economics and Statistics 77 (2): 251-266. http://dx.doi.org/10.2307/2109863

Lipkus, I. M., and E. Peters. 2009. "Understanding the Role of Numeracy in Health: Proposed Theoretical Framework and Practical Insights.” Health Education \& Behavior 36 (6): 1065-1081. http://dx.doi.org/10.1177/1090198109341533 (accessed November 10, 2015).

Lubienski, S. 2000. "A Clash of Social Class Cultures? Students' Experiences in a Discussion-Intensive Seventh-Grade Mathematics Classroom.” The Elementary School Journal 100 (4): 377-403. http://dx.doi.org/10.1086/499647

Madison, B. L., and L. A. Steen. 2008. Calculation vs. Context: Quantitative Literacy and its Implications for Teacher Education. Mathematical Association of America. Retrieved from https://www.maa.org/external archive/QL/cvc/CalcVsContext.pdf (accessed November 10, 2015).

Martin, D., M. Gholson, and J. Leonard. 2010. "Mathematics as Gatekeeper: Power and Privilege in the Production of Knowledge.” Journal of Urban Mathematics Education 3 (2): 12-24.

McBride, M. 1989. “A Foucauldian Analysis of Mathematical Discourse.” For the Learning of Mathematics 9(1): 40-46.

National Council of Teachers of Mathematics. 2000. Principles and Standards for School Mathematics. Reston, VA.

Olson, D. R. 1980. "On the Language and Authority of Textbooks.” Journal of Communication 30 (1): 186. http://dx.doi.org/10.1111/j.1460-2466.1980.tb01786.x (accessed November 10, 2015).

Orrill, R. 2001. "Mathematics, Numeracy, and Democracy.” In Steen (2001), xiii-xx.

Oughton, H. 2007. "Constructing the 'Ideal Learner': A Critical Discourse Analysis of the Adult Numeracy Core Curriculum.” Research in Post-Compulsory Education 12 (2): 259-275. http://dx.doi.org/10.1080/13596740701387536 (accessed November 10, 2015).

Rivera-Batiz, F. L. 1992. "Quantitative Literacy and the Likelihood of Employment among Young Adults in the United States.” Journal of Human Resources 27 (2): 313-328. http://dx.doi.org/10.2307/145737

Rogers, R. 2004. An Introduction to Critical Discourse Analysis in Education. Mahwah, NJ: Lawrence Erlbaum Associates.

Rothman, Russell L., Ryan Housam, Hilary Weiss, Dianne Davis, Rebecca Gregory, Tebeb Gebretsadik, Ayumi Shintani, and Tom A. Elasy. 2006. "Patient Understanding of Food Labels: The Role of Literacy and Numeracy.” American Journal of Preventive Medicine 31 (5): 391. http://dx.doi.org/10.1016/j.amepre.2006.07.025 
Scheaffer, R. L. 2008. "Scientifically Based Research in Quantitative Literacy: Guidelines for Building a Knowledge Base.” Numeracy 1 (1): Article 3. http://dx.doi.org/10.5038/1936-4660.1.1.3 (accessed November 10, 2015).

Seah, W. T., and A. J. Bishop. 2000. Values in Mathematics Textbooks: A View through Two Australasian Regions. Distributed by ERIC Clearinghouse.

Secada, W. 1989. “Agenda Setting, Enlightened Self-Interest, and Equity in Mathematics Education.” Peabody Journal of Education 66: 22-56. http://dx.doi.org/10.1080/01619568909538637 (accessed November 10, 2015).

Steen, L. A. (exec. ed). 1989. Reshaping College Mathematics: A Project of the Committee on the Undergraduate Program in Mathematics. Washington, DC: Mathematical Association of America.

- (exec. ed). 2001. Mathematics and Democracy: The Case for Quantitative Literacy. The Woodrow Wilson National Fellowship Foundation, National Council on Education and the Disciplines. http://www.maa.org/ql/mathanddemocracy.html

- 2004. Achieving Quantitative Literacy: An Urgent Challenge for Higher Education. Washington, DC: Mathematical Association of America.

Vacher, H. L. 2014. "Looking at the Multiple Meanings of Numeracy, Quantitative Literacy, and Quantitative Reasoning.” Numeracy 7 (2): Article 1. http://dx.doi.org/10.5038/1936-4660.7.2.1 (accessed November 10, 2015).

Wilkins, J. L. M. 2000. "Preparing for the 21st Century: The Status of Quantitative Literacy in the United States.” School Science and Mathematics 100: 405-418. http://dx.doi.org/10.1111/j.1949-8594.2000.tb17329.x

—. 2010. "Modeling Quantitative Literacy.” Educational and Psychological Measurement 70 (2): 267-290. http://dx.doi.org/10.1177/0013164409344506 (accessed November 10, 2015).

Zevenbergen, R. 1996. “Constructivism as A Liberal Bourgeois Discourse.” Educational Studies in Mathematics 31 (1): 95-115. http://dx.doi.org/10.1007/BF00143928

_. 1998. "Classroom Interaction and Linguistic Capital: A Bourdieuian Analysis of the Construction of Social Differences in Mathematical Education.” In Mathematics education and society: Proceedings of the first international mathematics education and society conference (MEAS1) 6-11 September 1998, ed P. Gates, 360-366. Nottingham: Centre for the Study of Mathematics Education, Nottingham University.

- 2000. “'Cracking the Code’ of Mathematics Classrooms: School Success as a Function of Linguistic, Social and Cultural Background.” In Multiple perspectives on mathematics teaching and learning, ed. J. Boaler, 201-223. Westport, CT: Ablex Publishing. 